\title{
Produção acadêmica em lutas, artes marciais e esportes de combate
}

\author{
Walter Roberto Correia ${ }^{1}$ \\ Emerson Franchini ${ }^{2}$ \\ ${ }^{1}$ Departamento de Pedagogia do Movimento do Corpo Humano da Escola de Educação \\ Física e Esporte da USP, São Paulo, SP, Brasil \\ ${ }^{2}$ Grupo de Estudos e Pesquisas em Lutas, Artes Marciais e Modalidades de Combate do \\ Departamento de Esporte da Escola de Educação Física e Esporte da USP, São Paulo, \\ $S P$, Brasil
}

\begin{abstract}
Resumo: O presente estudo objetivou analisar a produção acadêmica em lutas, artes marciais e esportes de combate nas principais revistas acadêmicas de circulação nacional da área de Educação Física, após o estabelecimento do sistema CONFEF, bem como analisar os temas destes artigos. A classificação quanto à sua temática seguiu a proposição de Tani (1996) para a estrutura acadêmica da Cinesiologia, Educação Física e Esporte. Dos 2561 artigos publicados nesses periódicos, apenas 75 (2,93\%) tratavam de Lutas/Artes Marciais/Modalidades Esportivas de Combate. Foi constatado o predomínio dos estudos conduzidos na área de Biodinâmica (40\%), seguidos pelos Estudos Socioculturais do Movimento Humano (32\%) e Comportamento Motor (8\%). Os estudos aplicados foram divididos em: Pedagogia do Movimento Humano (10,7\%), Treinamento Esportivo (8\%), Administração Esportiva (1,3\%) e Adaptação do Movimento Humano (nenhum artigo produzido). Esses dados indicam: (1) carência de publicações sobre essas atividades, especialmente as de caráter aplicado; (2) necessidade de investimento em pesquisas inter e multidisciplinares sobre essa temática.
\end{abstract}

Palavras-chave: Artes Marciais. Ciência. Estatística e dados numéricos.

\section{Academic papers about fight, martial arts and combat sports}

\begin{abstract}
The present study had as objective to verify the production of fight, martial arts and combat sports in articles published in the main Physical Education academic journals available in Brazil after the establishment of the CONFEF, as well as analyze the subjects studied in these articles. The subject classification followed Tani (1996)'s proposition concerning an academic structure to Kinesiology, Physical Education and Sport. When considering the 2561 articles published on these journals only 75 (2.93\%) were related to Fight/Martial Arts/Combat Sports. It was verified a predominance of studies conducted in the Biodynamic area (40\%), followed by Human Movement Socio-cultural Studies (32\%) and Motor Behavior (8\%). The applied studies were divided as: Human Movement Pedagogy (10.7\%), Sports Training (8\%), Sports Administration (1.3\%) and Adapted Human Movement (none study published). These data indicate: (1) a reduced number of publications concerning these activities, especially those of applied nature; (2) a need to promote inter and multidisciplinary research about this subject.
\end{abstract}

Key Words: Martial Arts. Science. Statistics and numerical data.

\section{Introdução}

O termo "Luta" de forma recorrente e dinâmica implica um investimento diversificado de representações e significados, o que por sua vez, Ihe confere uma dimensão polissêmica. Como exemplificação, temos as noções de lutas de classe, dos trabalhadores, pelos direitos da mulher, pela vida e outros mais. No sentido lato, temos a situação em que o referido termo se circunscreve no contexto dos embates físicos/corporais por intenções de subjugações entre os sujeitos a partir de conflitos interpessoais e, invariavelmente, por conteúdos humanos contraditórios e ambivalentes. "Arte Marcial" faz referência a um conjunto de práticas corporais que são configuradas a partir de uma noção aqui denominada de "metáfora da guerra", uma vez que essas práticas derivam de técnicas de guerra como denota o nome, isto é, marcial (de Marte, deus romano da guerra; Ares para os gregos) (FRANCHINI et al., 1996). Assim, a partir de sistemas ou técnicas diversas de combate situadas em diferentes contextos sociais, essas elaborações culturais passam por um autêntico processo de ressignificação, em que a dimensão ética e estética ganham uma expressiva proeminência. Desta forma podemos identificar que a expressão "arte" nos sinaliza para uma 
demanda expressiva, inventiva, imaginária, lúdica e criativa, como elementos a serem inclusos no processo de construção de certas manifestações antropológicas ligadas ao universo das Artes Marciais. Já o termo marcial, relacionado ao campo mitológico faz alusões à dimensão conflituosa das relações humanas. Assim, temos a inclusão contínua de elementos que ultrapassam as demandas pragmáticas e utilitaristas das formas militares e bélicas de combates. A denominação Modalidades Esportivas de Combate implica uma configuração das práticas de lutas, das artes marciais e dos sistemas de combate sistematizados em manifestações culturais modernas, orientadas a partir das decodificações propostas pelas instituições esportivas. Aspectos e conceitos como competição, mensuração, aplicação de conceitos científicos, comparação de resultados, regras e normas codificadas e institucionalizadas, maximização do rendimento corporal e espetacularização da expressão corporal são alguns exemplos dessa transposição moderna de práticas seculares de "combate". Sendo assim, se faz necessário nessa discussão, destacar que a não consensualidade vem demarcando e caracterizando a interlocução entre os diversos protagonistas que compõem a cena histórica que representa o campo das lutas, artes marciais e modalidades esportivas de combate (DEL VECCHIO, FRANCHINI, 2006; PUCINELI et al., 2005).

As lutas, as artes marciais e as modalidades esportivas de combate (L/AM/MEC) implicam um universo amplo de manifestações antropológicas de natureza mulidimensional e complexa. Como um conjunto de práticas socioculturais proveniente de um espectro diversificado de demandas históricas específicas, é possível identificar uma pluralidade muito patente nas suas diferentes configurações sociais, formas de expressão, repertório técnico, linguagens, organização e institucionalização. Nesta perspectiva, as lutas e as artes marciais podem ser vistas como construções identificadas e inerentes ao patrimônio cultural de diversos povos e, sobretudo, como um fenômeno relevante inserido na dinâmica da sociedade contemporânea e no processo da globalização (BACK; KIM, 1984; DONOHUE, 2005; GOODGER, 1982; STRATTON, 1986).
A demanda social pela prática destas manifestações pode ser evidenciada tanto no âmbito da cultura escolar, como na esfera social mais abrangente (não escolar) (DEL VECCHIO; FRANCHINI, 2006; WINKLE; OZMUN, 2003). No contexto da escolarização, as lutas são propostas como tema integrativo do currículo formal a partir das sinalizações da política educacional vigente. Como exemplo desta realidade, encontramos indicações nos Parâmetros Curriculares Nacionais (PCN) de Educação Física (BRASIL, MEC, 1997) e na Proposta Curricular de Educação Física do Estado de São Paulo (SÃO PAULO, CENP/SE, 2008), proposições para a sistematização do tema lutas/artes marciais nos contextos da Educação Infantil, do Ensino Fundamental e do Ensino Médio. Ainda nesta direção, é comum o oferecimento de programas de lutas no interior das escolas no âmbito do domínio extracurricular. No Ensino Superior, é muito freqüente a prática das lutas proporcionadas pelas atléticas e centros acadêmicos. No processo de preparação profissional encontramos as lutas, as artes marciais e os esportes de combate como disciplinas dos cursos de bacharelado e licenciatura em Educação Física, uma vez que a temática é prevista pelas diretrizes dos respectivos cursos (DEL VECCHIO; FRANCHINI, 2006).

No ambiente e na dimensão não escolar, essas práticas são realizadas por pessoas das diferentes fases do ciclo vital. Clubes, academias, institutos, condomínios, empresas, organizações não governamentais, centros esportivos municipais, praças públicas têm sido ambiências provedoras destas manifestações corporais e de movimento (COX, 1993; DEL VECCHIO; FRANCHINI, 2006; THEEBOOM; KNOP, 1999; WINKLE; OZMUN, 2003). As configurações sociais e suas respectivas representações estão inscritas sob diferentes codificações, ou seja, como atividade competitiva (Esporte), terapia, educação, aptidão física, lazer, recreação, programas de inclusão social, técnicas de defesa pessoal, etc. (BOTTENBURG; HEILBRON, 2006; BROWN; JONHSON, 2000; BURKE et al., 2007; COX, 1993; LANTZ, 2002; SKIDMORE, 1991). As modalidades esportivas de combate, especificamente, têm alcançado repercussão e visibilidade social por meio do seu engajamento em competições internacionais, tendo nos Jogos Olímpicos a expressão maior de sua 
apresentação como um fenômeno globalizado. Também nesta questão, podemos observar a demanda por profissionais qualificados que compreendam os princípios operacionais para adequação de aspectos associados à preparação física e orientação técnico-tática de atletas e organização e promoção de eventos dessa natureza (BACK; KIM, 1984; CARR, 1993; DEL VECCHIO; FRANCHINI, 2006; GOODGER, 1980; VILLAMÓN et al., 2004).

Como dado indicativo do processo de expansão e socialização das práticas relativas às lutas na vida cotidiana, fica patente a extensão e a intensidade da proliferação de federações e confederações representativas das diferentes modalidades ou sistemas de lutas, bem como a projeção pelos diferentes canais de mídia na disseminação de informação e de eventos ligados ao segmento. Revistas especializadas, programas televisivos, materiais para a prática, páginas na internet e, com especial destaque, a cinematografia, demonstram que o fenômeno se converte em um grande "empreendimento social" (BOTTENBURG; HEILBRON, 2006; FRANCHINI et al., 1996). Somando-se todas estas evidências, cabe aqui destacar os inúmeros projetos de lei procurando inserir e regulamentar as lutas, as artes marciais e os esportes de combate como elementos estratégicos das secretarias estaduais e municipais como parte do fomento de políticas de esporte, lazer, educação e cultura.

Contudo, muitas vezes a desinformação a respeito dessas atividades e a falta de profissionais qualificados para difundi-las, têm feito com que se crie uma imagem distorcida sobre as L/AM/MEC (FRANCHINI et al., 1996). Adicionalmente, com a criação do Conselho Federal de Educação Física (CONFEF), a maior parte dessas atividades passou a ser responsabilidade dos profissionais de Educação Física e daqueles que comprovadamente atuavam com essas atividades antes da criação desse conselho profissional (CONFEF, 2002). Em que pese discussões sobre o profissional que deve atuar nessa área, é preciso reconhecer que poucos cursos de graduação em Educação Física ou Esporte apresentam disciplinas específicas voltadas para as artes marciais e quando o fazem tratam quase que exclusivamente de uma ou duas modalidades, mais especificamente o judô e a capoeira (DEL VECCHIO; FRANCHINI, 2006). Além disso, existe uma carência muito grande sobre conhecimentos específicos referentes a essas atividades. Adicionalmente, entendendo a Educação Física como uma profissão academicamente orientada (BRESSAN, 1979; LIMA, 1994; MORFORD, 1972; IANI, 1996), pressupõe-se que uma das fontes de consulta de profissionais seja a leitura de artigos publicados em periódicos científicos. Neste sentido, o presente estudo objetivou verificar o número de artigos publicados nas principais revistas acadêmicas de circulação nacional da área de Educação Física após o estabelecimento do sistema CONFEF/CREF (i.e., nos últimos 10 anos), bem como analisar as temáticas estudadas nestes artigos.

\section{Materiais e Métodos}

A escolha dos periódicos foi baseada em questionamento a 17 profissionais/acadêmicos envolvidos simultaneamente com Educação Física e L/AM/MEC sobre quais periódicos nacionais eram consultados para obtenção de informação sobre as últimas atividades. Esse grupo possuía pessoas do segundo ano da graduação em Educação Física até mestres em Educação Física, com atuação nas seguintes manifestações culturais: Aikidô, Capoeira, Hapkidô, Jiu-jitsu, Judô, Kung fu, Karatê e Taekwondo. O envolvimento com essas atividades variava de participação em competição como atletas, atuação como preparadores físicos, professores, técnicos e pesquisadores. Todas essas pessoas eram participantes de um dos dois grupos de pesquisa relacionado à temática L/AM/MEC (Grupo de Estudos e Pesquisas em Lutas, Artes Marciais e Modalidades de Combate), conforme registro no Diretório de Grupos de Pesquisa do CNPq. Adicionalmente ao envolvimento com os estilos específicos de L/AM/MEC, os participantes do grupo possuíam inserção em diferentes linhas de pesquisa, a saber: aspectos biodinâmicos das L/AM/MEC, aspectos pedagógicos das L/AM/MEC e aspectos sócio-culturais das L/AM/MEC. Após esse levantamento, todos os periódicos citados que atendessem os critérios de inclusão no sistema Qualis da Coordenação de Aperfeiçoamento de Pessoal de Nível Superior e publicação de pelo menos 15 volumes publicados no período de 1998 a 2008 foram analisados. No total 11 periódicos da área de Educação Física, com diferentes classificações no Qualis, foram incluídos na presente análise, realizada em 
setembro de 2008. Foram analisados cinco periódicos classificados como Nacionais C (Conexões, Corpoconsciência, Motriz, Revista de Educação Física e Revista Mineira de Educação Física), dois periódicos classificados como Nacionais B (Revista Brasileira de Ciência e Movimento e Revista da Educação Física) e quatro periódicos classificados como Internacionais C (Movimento, Revista Brasileira de Ciências do Esporte, Revista Brasileira de Cineantropometria e Desempenho Humano e Revista Paulista de Educação Física/Revista Brasileira de Educação Física e Esporte). Para cada periódico foi determinado o número de volumes e número de artigos por ano. Os artigos que constassem termos associados às L/AM/MEC em seu título, resumo ou palavraschaves foram considerados como pertinentes para as análises do presente estudo, tendo a atividade central analisada também contabilizada.
A classificação dos artigos quanto à sua temática seguiu a proposição de Tani (1996) para a estrutura acadêmica da Cinesiologia, Educação Física e Esporte. Nessa classificação, os estudos de caráter básico são realizados pela Cinesiologia, tendo como diferentes níveis de análise a Biodinâmica do Movimento Humano, o Comportamento Motor Humano e os Estudos Sócio-Culturais do Movimento Humano. Os estudos de caráter aplicado seriam conduzidos, no caso da Educação Física, nas áreas de Pedagogia do Movimento Humano e Adaptação do Movimento Humano, ao passo que no Esporte, os estudos seriam conduzidos nas áreas de Treinamento Esportivo e Administração Esportiva. A escolha dessa classificação se deveu ao fato da mesma contemplar áreas historicamente consolidadas no campo da Educação Física/Esporte no âmbito da produção de conhecimento.

\section{Resultados}

A Tabela 1 apresenta o total de artigos publicados em cada periódico no período de 1998 a 2008, bem como o total de artigos com temática referente às L/AM/MEC.

Tabela 1. Total de artigos publicados em periódicos nacionais no período de 1998 a 2008 (número de artigos com temática associada às lutas, artes marciais e modalidades esportivas de combate).

\begin{tabular}{|c|c|c|c|c|c|c|c|c|c|c|c|c|}
\hline Periódico/ano & 1998 & 1999 & 2000 & 2001 & 2002 & 2003 & 2004 & 2005 & 2006 & 2007 & 2008 & Total \\
\hline Conexões & $\begin{array}{c}9 \\
(0)\end{array}$ & $\begin{array}{c}9 \\
(0)\end{array}$ & - & $14(0)$ & - & - & $12(0)$ & $11(0)$ & $13(1)$ & $14(0)$ & $71(5)$ & $\begin{array}{c}153 \\
(6)\end{array}$ \\
\hline Corpoconsciência & $12(1)$ & $11(1)$ & $11(0)$ & $\begin{array}{l}8 \\
(1)\end{array}$ & $\begin{array}{l}9 \\
(0)\end{array}$ & $\begin{array}{c}7 \\
(0)\end{array}$ & $\begin{array}{l}8 \\
(0)\end{array}$ & $\begin{array}{l}8 \\
(1)\end{array}$ & $\begin{array}{c}9 \\
(0)\end{array}$ & $10(1)$ & - & $\begin{array}{l}93 \\
(5)\end{array}$ \\
\hline Movimento & $16(0)$ & $21(1)$ & $18(0)$ & $29(0)$ & $21(0)$ & $27(0)$ & $28(0)$ & $32(0)$ & $33(0)$ & $33(3)$ & $23(1)$ & $\begin{array}{c}281 \\
(5)\end{array}$ \\
\hline Motriz & $15(0)$ & $30(1)$ & $13(0)$ & $14(1)$ & $20(0)$ & $25(1)$ & $22(1)$ & $23(0)$ & $35(0)$ & $35(1)$ & - & $\begin{array}{c}232 \\
(5)\end{array}$ \\
\hline RBCE & $52(0)$ & $24(1)$ & $29(0)$ & $36(1)$ & 39 (3) & $38(0)$ & $31(2)$ & $33(0)$ & $36(2)$ & $40(0)$ & $26(0)$ & $\begin{array}{c}384 \\
(9)\end{array}$ \\
\hline RBCM & - & - & $27(0)$ & $41(2)$ & $44(0)$ & $54(3)$ & $60(4)$ & $56(2)$ & $51(1)$ & $57(2)$ & - & 390 (14) \\
\hline $\mathrm{RBCDH}$ & - & $11(0)$ & $12(0)$ & $10(1)$ & $\begin{array}{c}9 \\
(0)\end{array}$ & $18(1)$ & $18(1)$ & $23(0)$ & $60(3)$ & $48(2)$ & $62(1)$ & $\begin{array}{c}271 \\
(9)\end{array}$ \\
\hline REF-UEM & $15(0)$ & $13(2)$ & $18(0)$ & $24(1)$ & $37(1)$ & $24(0)$ & $19(0)$ & $24(0)$ & $24(1)$ & $24(0)$ & $15(0)$ & $\begin{array}{c}237 \\
(5)\end{array}$ \\
\hline REF & $\begin{array}{l}5 \\
(1)\end{array}$ & $\begin{array}{c}0 \\
(0)\end{array}$ & $\begin{array}{l}4 \\
(0)\end{array}$ & $\begin{array}{l}6 \\
(1)\end{array}$ & $\begin{array}{l}6 \\
(1)\end{array}$ & $11(0)$ & $14(0)$ & $23(1)$ & $21(2)$ & $32(2)$ & $13(0)$ & $\begin{array}{r}135 \\
(8)\end{array}$ \\
\hline RMEF & $13(1)$ & $15(2)$ & $13(1)$ & $15(0)$ & $\begin{array}{c}5 \\
(0)\end{array}$ & $10(0)$ & $\begin{array}{l}8 \\
(0)\end{array}$ & $26(2)$ & $\begin{array}{l}0 \\
(0)\end{array}$ & - & - & $\begin{array}{c}105 \\
(6)\end{array}$ \\
\hline RPEF/RBEFE & $20(1)$ & $29(0)$ & $26(0)$ & $32(0)$ & $20(0)$ & $14(0)$ & $41(1)$ & $30(0)$ & $30(0)$ & $38(1)$ & - & $\begin{array}{r}280 \\
(3)\end{array}$ \\
\hline Total & $\begin{array}{c}157 \\
(4) \\
\end{array}$ & $\begin{array}{c}163 \\
(8) \\
\end{array}$ & $\begin{array}{c}171 \\
(1)\end{array}$ & $\begin{array}{c}229 \\
(8) \\
\end{array}$ & $\begin{array}{c}210 \\
(5) \\
\end{array}$ & $\begin{array}{c}228 \\
(5) \\
\end{array}$ & $\begin{array}{c}261 \\
(9) \\
\end{array}$ & $\begin{array}{c}289 \\
(6) \\
\end{array}$ & $\begin{array}{l}312 \\
(10) \\
\end{array}$ & $\begin{array}{l}331 \\
(11) \\
\end{array}$ & $\begin{array}{c}210 \\
(7)\end{array}$ & $\begin{array}{c}2561 \\
(75) \\
\end{array}$ \\
\hline
\end{tabular}

RBCE = Revista Brasileira de Ciências do Esporte; RBCM = Revista Brasileira de Ciência e Movimento; $\mathrm{RBCDH}=$ Revista Brasileira de Cineantropometria e Desempenho Humano; REF-UEM = Revista da Educação Física; REF = Revista de Educação Física; RMEF = Revista Mineira de Educação Física; RPEF/RBEFE = Revista Paulista de Educação Física/Revista Brasileira de Educação Física e Esporte.

Do total de artigos publicados nos periódicos consultados, apenas 75 (2,93\%) abordavam a temática L/AM/MEC. Destes 75 artigos, 37 abordavam o Judô (49,3\%), 18 (24\%) a Capoeira, cinco (6,7\%) o Karatê, cinco diversas lutas (6,7\%), quatro (5,3\%) a Esgrima, dois $(2,7 \%)$ o Jiu-jitsu, dois $(2,7 \%)$ o Tai-chi-chuan, um $(1,3 \%)$ o Taekwondo e um (1,3\% a Luta Olímpica). 
A Tabela 2 apresenta a classificação dos artigos.

Tabela 2. Classificação dos artigos com a temática lutas, artes marciais e modalidades esportivas de combate, publicados em periódicos nacionais entre 1998 e 2008, segundo a estruturação acadêmica proposta por Tani (1996).

\begin{tabular}{|c|c|c|c|c|c|c|c|c|c|c|c|c|}
\hline Tema/ano & 1998 & 1999 & 2000 & 2001 & 2002 & 2003 & 2004 & 2005 & 2006 & 2007 & 2008 & Total \\
\hline $\begin{array}{l}\text { Biodinâmica do } \\
\text { Movimento Humano }\end{array}$ & 1 & 4 & - & 5 & 2 & 1 & 5 & 5 & 3 & 4 & - & 30 \\
\hline $\begin{array}{l}\text { Comportamento } \\
\text { Motor }\end{array}$ & 1 & - & - & - & 1 & - & - & 1 & 1 & 1 & 1 & 6 \\
\hline $\begin{array}{l}\text { Estudos sócio- } \\
\text { culturais do } \\
\text { movimento humano }\end{array}$ & 1 & 3 & 1 & 1 & 1 & 3 & 2 & - & 5 & 5 & 2 & 24 \\
\hline $\begin{array}{l}\text { Pedagogia do } \\
\text { Movimento Humano }\end{array}$ & 1 & 1 & - & 1 & 1 & - & - & - & 1 & 2 & 1 & 8 \\
\hline $\begin{array}{l}\text { Adaptação do } \\
\text { movimento humano }\end{array}$ & - & - & - & - & - & - & - & - & - & - & - & - \\
\hline $\begin{array}{l}\text { Treinamento } \\
\text { esportivo }\end{array}$ & - & - & - & 1 & - & 1 & 1 & - & - & - & 3 & 6 \\
\hline $\begin{array}{l}\text { Administração } \\
\text { esportiva }\end{array}$ & - & - & - & - & - & - & 1 & - & - & - & - & 1 \\
\hline
\end{tabular}

Com base na Tabela 2 é possível constatar o predomínio dos estudos conduzidos na área de Biodinâmica (40\%), seguidos pelos Estudos Sócio-Culturais do Movimento Humano (32\%) e Comportamento Motor (8\%). Os estudos de caráter mais aplicado, isto é, Pedagogia do Movimento Humano (10,7\%), Treinamento Esportivo (8\%), Administração Esportiva (1,3\%) e Adaptação do Movimento Humano (nenhum artigo produzido), mesmo quando somados totalizam apenas $20 \%$ dos trabalhos publicados sobre a temática. Assim, do total de artigos publicados, apenas $15(0,58 \%)$ eram pesquisas aplicadas direcionadas às L/AM/MEC.

\section{Discussão}

Os resultados apontam para um baixo número de artigos direcionados às atividades de L/AM/MEC. Dentre esses artigos, a maior parte foi direcionada à análise do judô e da capoeira, o que reflete a tradição dessas atividades no Brasil. $O$ judô em decorrência da forte presença japonesa no país, conjuntamente com a tradição olímpica que a modalidade apresenta em nosso contexto (FRANCHINI, 2008). No que diz respeito à capoeira, é importante destacar que a mesma é considerada patrimônio cultural pelo Ministério da Cultura (FALCÃO, 2009; VIEIRA; ASSUNÇÃO, 2009), face sua forte inserção social em decorrência de sua origem e desenvolvimento no Brasil (VIEIRA, 2006).
Quanto à estrutura acadêmica proposta por Tani (1996), a maior parte dos artigos são relacionados às áreas de Biodinâmica do Movimento Humano e Estudos Sócio-Culturais do Movimento Humano, ambas com tradição de pesquisa na Educação Física brasileira.

Contudo, assim como ocorre em outras subáreas da Educação Física (Aprendizagem Motora, por exemplo, CHRISTINA, 1989) e na Educação Física de forma geral (BRESSAN, 1979), o número de pesquisas aplicadas direcionadas às L/AM/MEC é bastante reduzido. De fato, levantamento sobre artigos relacionados à Educação Física Escolar (ANTUNES et al., 2005) demonstrou que poucos artigos são direcionados a essa temática e, mais do que isso, poucos são direcionados a aspectos além da caracterização. Os autores apontam o distanciamento entre pesquisadores e professores, uma vez que os objetos de estudo, as linguagens, as condições de elaboração do conhecimento e as especificidades profissionais são distintas, levando para uma dificuldade na interlocução acadêmica e profissional. Como exemplo desse quadro, temos uma situação expressa por aqueles que atuam no segmento escolar não sabem o que os pesquisadores produzem e esses últimos não sabem como os profissionais atuam. Esse cenário pode ser transposto para as questões das L/AM/MEC e traz sérias implicações sobre a qualidade do 
serviço prestado, bem como sobre a pertinência dos conhecimentos produzidos sobre esse tipo de atividade motora.

A partir dos dados apresentados neste estudo, podemos sublinhar a necessidade premente de ampliação e diversificação na produção de conhecimento acadêmico relativo ao universo das L/AM/MEC. A análise aqui realizada nos autoriza a indicação de ações investigativas de natureza inter e multidisciplinar, incorporando como objetos de estudo um espectro mais plural e diverso das manifestações corporais circunscritas no contexto acima citado. Ainda nesta perspectiva, entendemos como um fator determinante para uma interface sustentável e profícua entre as esferas das L/AM/MEC com a Educação Física, a orientação de pesquisas que tenham como foco, a dimensão da intervenção profissional e dos respectivos saberes de caráter aplicado.

A compreensão da multidimensionalidade destas manifestações corporais implica na mobilização de saberes das mais diversas áreas, bem como na utilização de procedimentos metodológicos especializados. Para que as L/AM/MEC sejam concebidas como manifestações culturais relevantes e transcendam as representações do senso comum e o teor "exótico" que lhes são conferidos (FRANCHINI et al., 1996), é preciso que o conhecimento crítico, sistemático e rigoroso do ponto de vista epistemológico seja produzido e, sobretudo, compartilhado socialmente entre os diferentes interlocutores e protagonistas destas atividades (DEL VECCHIO; FRANCHINI, 2006).

Estas questões interessam aos profissionais de Educação Física em duas direções, ou seja, tanto para o campo de intervenção dos licenciados como para o contexto das práticas profissionais dos bacharéis. $\mathrm{Na}$ esfera dos profissionais licenciados em Educação Física, o respectivo componente curricular do Ensino Básico, dispõe de sinalizações curriculares provenientes da política educacional vigente, nas quais são propostas sistematizações de conteúdos relativos às L/AM/MEC. Considerando as prescrições oficiais de ensino, isto é, os PCN de Educação Física (BRASIL/ MEC, 1997), a atual Proposta Curricular do Estado de São Paulo (SÃO PAULO, 2008) e algumas abordagens de ensino como Coletivo de Autores (1992), podemos presumir como os conhecimentos sistematizados sobre as múltiplas dimensões das
L/AM/MEC, são imprescindíveis para oferecer suporte teórico aos professores e professoras, tanto no âmbito da formação inicial como na permanente. Considerando o alcance dessas proposições oficiais, bem como a escassez de cursos de licenciatura e/ou formação continuada que proponham a tematização das L/AM/MEC/, fica evidente a importância da produção de conhecimento para alicerçar uma condição mínima de apoio aos docentes, na eminência da elaboração dos saberes necessários á prática educativa. As L/AM/MEC incorporam uma ampla variedade de manifestações, o que implica linguagens, lógicas, técnicas, procedimentos, valores e racionalizações muito distintas. Muitas dessas formas de cultura corporal não foram construídas para o ambiente escolar, para uma sociedade do "Estado de Direito" e, principalmente, para crianças e adolescentes em processo de formação. Mesmo que admitamos possíveis contribuições aos diferentes sujeitos, presumimos a necessidade de uma transformação didática e pedagógica na perspectiva dos fazeres e saberes escolares. Assim, consideramos necessário um "lastro de conhecimento" para que o ensejo seja contemplado de maneira minimamente satisfatória. O presente estudo indica uma restrição no montante das produções científicas, além de restrições temáticas e dimensionais, oferecendo, por sua vez, dados para uma problematização na esfera da compreensão da complexidade e da diversidade das L/AM/MEC como objeto de estudo e aplicação para Educação Física.

No contexto não escolar, para que haja uma eficiente preparação física, técnica, tática e organizacional das L/AM/MEC, além das dimensões já supracitadas, é preciso que haja um nível mínimo e diversificado de descrições e análises das modalidades ou manifestações de interesse. Nos clubes, nas academias, ou ainda, nos programas de lazer e recreação, podemos identificar demandas do ponto de vista do planejamento, gerenciamento e supervisão para implementação de programas de L/AM/MEC, o que por sua vez, implica conhecimentos de suporte e referências aos profissionais do Esporte, da Educação Física e do Lazer. Na esfera das práticas educativas com objetivos relativos à saúde pública ou qualidade de vida, o estudo das lutas e artes marciais são indispensáveis para a superação do senso 
comum que impera nos diferentes canais de comunicação social de massa. Assertivas como: Arte Marcial é saúde e qualidade de vida; defesa pessoal eficiente; disciplina para crianças e jovens; espiritualidade; são milenares e providas de filosofias; preconizam a paz social; são exemplos de que, todos esses anúncios disponibilizados na sociedade contemporânea, suscitam o crivo da reflexão criteriosa e sistematizada do instrumental científico e do espírito crítico, para que profissionais, no uso de suas atribuições, possam legitimar um compromisso social.

É necessário encarar a realidade com uma abordagem crítica e rigorosa do ponto de vista epistemológico, para que possamos vislumbrar uma ação responsável e qualificada diante da realidade social vigente. Desconsiderando essa prerrogativa, qualquer reivindicação de intervenção e controle social sobre as práticas profissionais e educativas nos campos das L/AM/MEC implicará uma proposição de cunho arbitrário e de qualificação passível de questionamento. O debate e as reivindicações devem estar ancorados, inexoravelmente, num processo de elaboração de conhecimento crítico e sistematizado de forma a superarmos as armadilhas do formalismo "legal-burocráticocorporativo".

Entretanto, é importante destacar que historicamente a Educação Física dispõe de um acúmulo de conhecimentos teóricos e práticos relacionados ao movimentar-se humano (LIMA, 1994) e a cultura corporal de movimento (DAOLIO, 2004), que indiscutivelmente interessam aos propósitos de desenvolvimento das manifestações abordadas neste estudo. Ainda nessa perspectiva, convém ressaltarmos que a Educação Física do ponto de vista acadêmico não se apropriou das manifestações L/AM/MEC de forma minimamente satisfatória face ao dinamismo, à complexidade, à pluralidade e à presença premente dessas atividades corporais no âmbito da cultura brasileira e global.

\section{Considerações Finais}

Com base no levantamento efetuado foi possível analisar a produção acadêmica dos periódicos nacionais em Educação Física sobre a temática L/AM/MEC, a partir dos quais identificamos uma significativa precariedade restritiva do conhecimento científico nas dimensões quantitativas e qualitativas. Como evidência, apontamos para presença de poucas pesquisas de cunho aplicado do ponto de vista da intervenção profissional e sócio-educativa, cujo direcionamento esteve circunscrito num viés da Biodinâmica do Movimento Humano ou dos Estudos Sócio-culturais da Educação Física em poucas manifestações da cultura corporal (e.g., Capoeira e Judô) relacionadas às L/AM/MEC. Assim sendo, não reconhecemos como algo plausível e consistente, qualquer reivindicação de exclusividade, subordinação ou hegemonia no âmbito do exercício profissional junto às L/AM/MEC, sobretudo com um quadro de limitações patentes do ponto de vista de uma produção acadêmica incipiente. Sendo assim, dada a relevância social das manifestações corporais e de movimento mencionadas por esse estudo, entendemos que a Educação Física pode contribuir com a sociedade a partir de uma intenção deliberada e consciente dos limites e possibilidade do conhecimento que lhe cabe ensejar na direção das "artes de combate", para que superemos os "embates" corporativos, na perspectiva de um "debate" promissor.

Como um possível posicionamento propositivo, sugerimos a efetivação de uma aproximação crítico-dialógica do ponto de vista acadêmico e profissional por parte dos múltiplos agentes que dinamizam e reconfiguram as manifestações corporais e de movimento, mais especificamente as relacionadas com L/AM/MEC, a partir do respeito e do reconhecimento dos múltiplos saberes que compõem a "grande teia" expressa pela diversidade cultural.

Sem um aporte de conhecimentos críticos e, sobretudo, desprovidos de saberes profissionalmente aplicados, a assertiva e o pleito de uma subordinação das práticas das L/AM/MEC aos ditames corporativos, no nosso entendimento, expressam uma proposição ilegítima.

\section{Referências}

ANTUNES, F. H.C.; DANTAS, L.E. P.B.T.; BIGOTTI, S.; TOKUYOSHI, J.H.; TANI, G.; BRASIL, F.K.; ANDRÉ, M. Um retrato da pesquisa brasileira em Educação Física escolar: 1999 - 2003. Motriz, Rio Claro, v.11, n.3, p. 179184, 2005.

BACK, A.; KIM, D. The future course of the Eastern martial arts. Quest, v.36, p.7-14, 1984. 
BOTTENBURG, M.V.; HEILBRON, J. Desportization of fighting contests - the origins and dynamics of no holds barred events and the theory of sportization. International Review for the Sociology of Sport, Otago, v. 41, n.3-4, 259282, 2006.

BRASIL. Ministério da Educação e Cultura. Parâmetros curriculares nacionais. Brasília: MEC, 1997.

BRESSAN, E.S. 2001: the profession is dead was it murder or suicide? Quest, Champaign, v.31, n.1, p.77-82, 1979.

BROWN, D.; JOHNSON, A. The social practice of self-defense martial arts: applications for physical education. Quest, Champaign, v.52, p.246-59, 2000.

BURKE, D.T.; AL-ADAWI, S.; LEE, Y.T.; AUDETTE, J. Martial arts as sport and therapy. Journal of Sports Medicine and Physical Fitness, Torino, v.47, n.1, p.96-102, 2007.

CARR, K. G. Making way: war, philosophy and sport in japanese judo. Journal of Sport History, Los Angeles, v. 20, n. 2, p. 167-188, 1993.

CHRISTINA, R. Whatever happened to applied research in motor learning? In: J. S. Skinner et alii (eds.) Future directions in exercise and sport science research.Champaign, ILL: Human Kinetics, 1989.

\section{CONSELHO FEDERAL DE EDUCAÇÃO FÍSICA.} Artes Marciais. Revista E.F., Rio de Janeiro, n.3, ano 1, p.3-9, 2002.

COX, J.C. Traditional Asian martial arts training: a review. Quest, v. 45, p.366-388, 1993.

DAOLIO, J. Educacação Física e o conceito de cultura. Campinas/SP: Autores Associados, 2004.

DEL'VECCHIO, F. B.; FRANCHINI, E. Lutas, artes marciais e esportes de combate: possibilidades, experiências e abordagens no currículo de educação física. In: SAMUEL DE SOUZA NETO; DAGMAR HUNGER (Org.).

Formação profissional em Educação Física: estudos e pesquisas. Rio Claro: Biblioética, 2006, v. 1, p. 99-108.

DONOHUE, J.J. Modern educational theories and traditional Japanese martial arts training methods. Journal of Asian Martial Arts, v.14, n.2, p.8-29, 2005.

FALCÃO, J. L. C. A internacionalização da capoeira. Revista Textos do Brasil, Ministério das Relações Exteriores, v.14, p.123-133, 2009.
FRANCHINI, E. Judô. São Paulo: Odysseus, 2008.

FRANCHINI, E.; DEL'VECCHIO, F. B. Tradição e modernidade no judô: histórico e implicações. In: KÁTIA RUBIO; ALBERTO REPPOLD FILHO; ROBERTO MALUF MESQUITA; NELSON TODT (Org.). Ética e compromisso social nos Estudos Olímpicos. Porto Alegre: Editora PUCRS, 2007, v. 1, p. 121-145.

FRANCHINI, E.; TAKITO, M.Y.; RODRIGUES, F.B.; MANOEL, E.J. Considerações sobre a inclusão de atividades motoras típicas de artes marciais em um programa de Educação Física. Proceedings do II Congresso de Iniciação Científica da Escola de Educação Física da Universidade de São Paulo, 1996. p. 65-69.

GOODGER, J.M. Theories of change in sport: comments on some recent contributions. International Review for the Sociology of Sport, Otago, v. 17, n.3, p.99-109, 1982.

GOODGER, B. C.; GOODGER, J. M. Organisational and cultural change in post-war British judo. International Review of Sport Sociology, Otago, v. 1, n. 15, p. 21-48, 1980.

LANTZ, J. Family development and the martial arts: a phenomenological study. Contemporary Family Therapy, Baltimore, v.24, n.4, p.565-580, 2002;

LIMA, J. R. P. Caracterização acadêmica e profissional da Educação Física. Revista Paulista de Educação Física, São Paulo, v.8, n.2, p. 54-67, 1994.

MORFORD, W. R. Toward a profession, not a craft. Quest, Champaign, Monograph XVIII, spring issue, p. 8-93, 1972.

PUCINELI, F.A.; NAKAMOTO, H.O.; DEL VECCHIO, F. B. Luta - Conceituação e Classificação. In: Anais do $1^{\circ}$ Congresso Internacional de Ciências do Esporte. Porto Alegre: Editora da URGS, 2005. p. 1128.

SÃO PAULO. Secretaria de Estado da Educação de São Paulo. Proposta Curricular de Educação Física. São Paulo: CENP/SP, 2008.

SKIDMORE, M.J. Oriental contributions to Western popular culture: the martial arts. Journal of Popular Culture, Baltimore, v.25, n.1, p.129148, 1991.

STRATTON, R. Of monks and warriors: a layman's overview of far eastern martial arts. Olympic Review, Lausanne, n.224, p.342-347, 1986. 
TANI, G. Cinesiologia, educação física e esporte: ordem emanente do caos na estrutura acadêmica. Motus Corporis, Rio de Janeiro, v. 3, n. 2, p. 9-49, 1996.

THEEBOOM, M.; KNOP, P. Asian martial arts and approaches of instruction in Physical Education. European Journal of Physical Education,

Berlin, v. 14, n.2, p.146-161, 1999.

VIEIRA, S. L. S. Capoeira. In: DaCosta, L. (Ed). Atlas do Esporte no Brasil. Rio de Janeiro: Shape, 2006. p.144-145.

VIEIRA, L. R.; ASSUNČ̃̃O, M.R. Os desafios contemporâneos da capoeira. Revista Textos do Brasil, Ministério das Relações Exteriores, v.14, p.9-19, 2009.

VILLAMÓN, M.; BROWN, D.; ESPARTERO, J.; GUTIÉRREZ C. Reflexive Modernization and the Disembedding of Judo from 1946 to the 2000 Sydney Olympics. International Review for the Sociology of Sport, Otago, v.2, n.39, p. 139156, 2004.

WINKLE, J.M.; OZMUN J.C. Martial arts: an exciting addition to the Physical Education curriculum. JOPERD, Chicago, v. 74, n.4, p.29$35,2003$.

Endereço:

Walter Roberto Correia

Av. Prof. Mello Moraes, 65 - Cidade Universitária São Paulo SP Brasil

05508-030

e-mail: wr.correia@usp.br efranchini@usp.br

Recebido em: 01 de julho de 2009.

Aceito em: 06 de novembro de 2009.

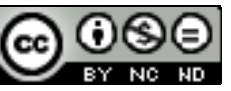

Motriz. Revista de Educação Física. UNESP, Rio Claro, SP, Brasil - elSSN: 1980-6574 - está licenciada sob Licenca Creative Commons 